\title{
Relationship between Social Well-being and Health Related Quality of Life Level among Senior Retirees of Tehran University of Medical Sciences
}

\author{
Sogand Torani ${ }^{1}$, Bahram Delgoshaei ${ }^{1}$, Agha Fatemeh Hosseini ${ }^{2}$, Hajar Ziaeifar ${ }^{3} \&$ Mehdi Raadabadi $^{4}$ \\ ${ }^{1}$ Department of Health Services Management, School of Health Management and Information Sciences, \\ Iran University of Medical Sciences, Tehran, Iran \\ ${ }^{2}$ Department of Mathematics \& Statistics- School of Management \& Medical Information, Iran University of \\ Medical Science, Tehran, Iran \\ ${ }^{3}$ Department of Health Management and Economies, School of Public Health, Tehran University of Medical \\ Science, Tehran, Iran \\ ${ }^{4}$ Health Services Management Research Center, Institute for Futures Studies in Health, Kerman University of \\ Medical Sciences, Kerman, Iran \\ Correspondence: Hajar Ziaeifar, Tehran University of Medical Sciences, Bolvar Keshavarz St. GHods St., Tehran, \\ Iran. E-mail: mh.ziaeefar@gmail.com
}

Received: December 30, 2014 Accepted: February 2, 2015 Online Published: June 5, 2015

doi:10.5539/ass.v11n18p116

URL: http://dx.doi.org/10.5539/ass.v11n18p116

\begin{abstract}
Introduction: Senior citizens or the elderly people are a group of people in the society considered as a growing population with special needs in the developed contemporary world. Since they have special needs, it is essential to care about the quality of their life because of the dangers which threaten them. Since the social health of the retirees is decreased as a result of exiting from the workplace and directly affecting their life quality, the researcher has done the present study.
\end{abstract}

Methodology: This paper which is a descriptive- analytic study has been periodically done in the second half of 2013. The participants were 227 senior retirees of Tehran University of Medical Sciences. The data have been collected through a reliable and valid questionnaire of life quality related to health (sf-36) and social well-being of KEYES. The data then were analyzed using SPSS.19 and descriptive statistics and paired t-test, one way ANOVA test and Pearson correlation were use as well.

Findings: There is a significant linear relation between life quality variable related to the health and social well-being components $(\mathrm{P}<0.05)$. There is also a significant correlation between the variables like age, sex, marital status, duration of employment and life quality.

Results: Regarding the findings of the study, it seems that the policy makers and planners need to create a kind of active integration and balance in society according to the available devices and facilities, and try to apply a proper information system to eliminate the cultural problems, reinforce the social relations and coherences in order to increase the life quality of senior retires.

Keywords: senior retirees, life quality, social well-being

\section{Introduction}

The increase of life expectancy and the decrease of child birth result in growing the number of retired people all over the world in a way that it has been changed to one of the most important challenges of public health in the present years. Growing the number of retired people is not specific to the developed countries but it is a phenomenon with which the developing countries also have encountered (Salehi, Salaki, \& Alizadeh, 2012). So, regarding to the increase of longevity index and life expectancy, the most important issue been raised is how to live or the life quality about which so many scholars and researchers have done researches (Ahmadi, Salar, \& Faghihzadeh, 2004). 
The phenomenon of getting old and its social and biologic process which naturally disorders the performance of different organs and also weaken the body, causes the person not to be able to manage his personal affairs and be a normal social entity. The effect of these inadequacies will be more salient in the social dimension of senior citizens' life, while the social life of the people significantly affects the life generally and the life quality specifically (Alipor, Sajadi, Forozan, \& Biglarian). According to the fact that, the life quality can be easily threatened in the elderly period, it is potentially important to consider the effective factors (Vahdaninia, Goshtasbi, Montazeri, \& Maftoun, 2005). The significant features of life quality are being multidimensional, mindful and active. These three aspects are the base of life quality related to the physical, mental and social health (Oliver, Huxley, Bridges, \& et al., 1997).

Social well-being is defined as mental, individual and social health. In case of the fulfillment of social well-being, the citizens will be motivated and happy and consequently the society will be healthy. In fact, the healthy life is the result of social interaction between the personal choices on one hand and social and economic environment which encircle the people on the other hand (Nikvarz, 2011). KEYES defines the social well-being in five dimensions of social integration, social acceptance, social contribution, social actualization and social coherence and states that as the age increases, the level of five mentioned dimension increase except the social coherence (Callaghan, 2008).

Goldsmith introduces the social well-being as one of the most basic health indexes of each country which leads to the efficiency of each individual in the society (McGregor \& Goldsmith, 1998). One of the main reasons of doing this research is that senior citizens are the subjects to be exposed by increasing dangers because of their problems like getting retired, loneliness and ostracism (Maddah, 2009).

Senior citizens or the elderly people are often defined as citizens aged more than the retirement age but the retirement age is different from country to country. Most of low-paid people still work even after the retirement age. The international activity plan of elderly's field of the World Elderly Community, has declared that the elderly refers to the people aged more than 60 years old. While in most of the countries, 60 year old people can easily cope with their personal affairs. In fact, some countries do not apply the obligatory age of retirement. Besides, it has been announced that the performance capability is much more important for political purposes than the real age (Improving the Quality of Life of Elderly and Disabled People in Human Settlements, 1993).

Compared with the developed countries, the developing countries like Iran will be more seriously faced with population growth of the elderly because their population is now young. The national census done in Iran has also approved the population growth of the elderly (Darvishpoor Kakhki, Abed Saeedi, Delavar, \& Saeed-O-Zakerin, 2010). It also should be mentioned that the old population will be more evident after 1415. In this case it can be said that the proportion of the elderly people above 60 years old and more will increase from the present $7 \%$ to $14.5 \%$ in 1415 and $22 \%$ in 1425 (Zilochi, PorReza, \& Akbari, 2011).

Although getting old does not mean getting sick and incapable, the elderly are more subject to get sick compared with the youth. Therefore, the old age is a very specific critical period in which the health care should be of high importance (Ishaghi \& Zamani, 2011).

A similar paper which has studied the relationship between the social well-being and social support among the elderly has concluded that the people's aging is along with the decrease of their social well-being (Usefy et al., 2010). A lot of researches have been done about the life quality of the elderly in different cities of the country. One of them is Yazdan Poor's study which demonstrates that the health dimensions affect the objective and mental dimensions of life quality (Montazeri, Goshtasbi, \& Vhdany Nia, 2005).

The concept of well-being is closely related to the concept of the quality of life. Both concern the satisfaction of material, biological, psychological, social, and cultural needs and demands of an individual, which are necessary for his satisfaction with life. Under the term of well-being rather the immediately experienced state may be understood whereas the quality of life concerns the more complex condition enabling satisfaction with life, which is of longer time duration and of a certain positive perspective respectively. From these points of view, health may be considered as the vital factor as concerns the capability of an individual to meet his aspirations and satisfy his needs and demands, and to manage the requirements of the biological and social environment as well.

Todays, examining the life quality in the clinical researches is very important and is regarded as one of the evaluation criterion in defining and evaluation the needs and also improving the people health. In the present situation which the inflation and sanctions affect the life quality of people and the most amount of impact is on the low paid people's life and the retired elderly are also among the low paid people, it is crucial to get informed about the social well-being of the retired elderly in order to plan properly to improve the life quality of the 
retired elderly in the country. The researcher also hopes to provide effective results through determination of a relation between the social well-being and the elderly's life quality.

\section{Method}

The present study is an analytic research which has been done in 2013. The participants were the members of the center of retirement of the Medical Science University of Tehran. The participants were the people who got retired between 1982- 1997 and they held different degrees like diploma and less, associate degree, bachelor degree, master degree, $\mathrm{PhD}$, faculty member and all different medical science degrees, administrative, support and research members of retirement center of Medical Science University of Tehran.

In order to estimate the sample size, the type I error defaults $(\alpha)$ equals with 0.05 and consequently the value of

$\mathrm{z}_{1-\frac{\alpha}{2}}$ will be 1.96 , the type II error $(\beta)$ equals will 0.2 and consequently the value of $\mathrm{Z}_{1-\beta}$ will be 0.84 , were

used. The value of $\mathrm{d}$ was computed according to the $\delta_{0}=\frac{1}{2} L_{n} \frac{1+r}{1-r}$. The correlation coefficient was considered $\mathrm{r}=0.218$ based on the previous studies and also regarding the formula of size determination of correlational studies, the number of samples were regarded 226 people. The sampling was also done according to the available sampling.

The data collection instruments included KEYES social well-being questionnaires and life quality questionnaire. Different questionnaires evaluate the life quality for example the life quality of World Health Organization (WHO) (Sharifirad, Khalili, Sam, Hassanzadeh, \& Kazemi, 2011) and LIPAD life quality (Alipor et al.). While the most common and comprehensive general standard instrument is Health-Related Quality of Life is a 36 question questionnaire named SF-36 which is internationally used as a standard instrument in order to evaluate the health level. According to Montazeri et al study which was done in order to evaluate the reliability and validity of the Short Persian Form Health Survey (SF-36), it has been shown that the Persian form of the questionnaire was reliable and valid enough to evaluate the life quality related to health. Besides, the efficiency of the questionnaire in the related researches such as evaluation of health policies, the relative estimation of different disease, screening of the patients and separation of the usage effects and also economic evaluations, different remedies, the intervention of health care as advising in the allocation of sources in the social level has been demonstrated (Hatami, 2010).

In most of the studies done on the social well-being in Iran, the translated form of KEYES model was used. The reliability and validity of the questionnaire of KEYES model was also evaluated (KEYES, 1998; Nikvarz, 2011; Usefy et al., 2010). The life quality scales related to health include physical health (physical health + physical limitation + physical pain + general health) and mental health (social performance + mental problems + mind health + happiness) (Hatami, 2010). KEYES proposes the social well-being dimensions according to the health pattern. The reliability and validity of KEYES social well-being questionnaire and the SF-36 questionnaire has been evaluated in many different studies (Hatami, 2010; KEYES, 1998; Moheghi Kamal, Sajadi, Zare, \& Biglarian, 2008). The questionnaires were filled out by the elderly who got retired in 1982-1997 and recourse to the retirement center in the second half of the 2013. After the filling out of the questionnaires and also collecting the data, the SPSS.19, was used in order to analyze data; besides, the descriptive statistics elements like frequency, mean and standard deviation and also Pearson correlation test, independent $T$ and variance analysis were employed to fully analyze the data.

\section{Results}

Among 227 the elderly people who were studied, $48 \%$ were women of whom $16 \%$ were single, $70 \%$ were married and the rest were widow. $3.1 \%$ of the participants were faculty members, $45.4 \%$ worked as the medical staff of the health care centers, $27.3 \%$ were the administrative staff, $44 \%$ worked as the training staff, $2.6 \%$ were the technical staff and $16.7 \%$ worked out as the service forces. $25 \%$ of the participants' retirement duration was less than 9 years, $50 \%$ of them less than $113 \%, 75 \%$ less than 17 years and finally $100 \%$ of them had retirement experience of less than 34 years. $11.7 \%$ of the participants had diploma degree or less than it which were the old staff of the centers, among which some had assistant degree, $17.5 \%$ of them had associate degree, $62.6 \%$ held bachelor degree, $2.7 \%$ held master and the other 5.6\% held $\mathrm{PhD}$ in medical science, laboratory science and medicine (Table 1). 
The mean and standard deviation of all the dimensions of social well-being and life quality was computed by using the questionnaire. According to the findings, among the social well-being components, the most and the least mean and standard deviation is respectively related to social acceptance $(0.94 \pm 3.5)$ and social integration $(0.83 \pm 2.3)$. The mean and standard deviation of social well-being is $25.7 \pm 66.3$ and the mental health is 21.6 \pm 68.8 . Totally, the mean and standard deviation of life quality is $21.3 \pm 68.8$ (Table 2 ).

Table 1. Demographic information of the under study elderly

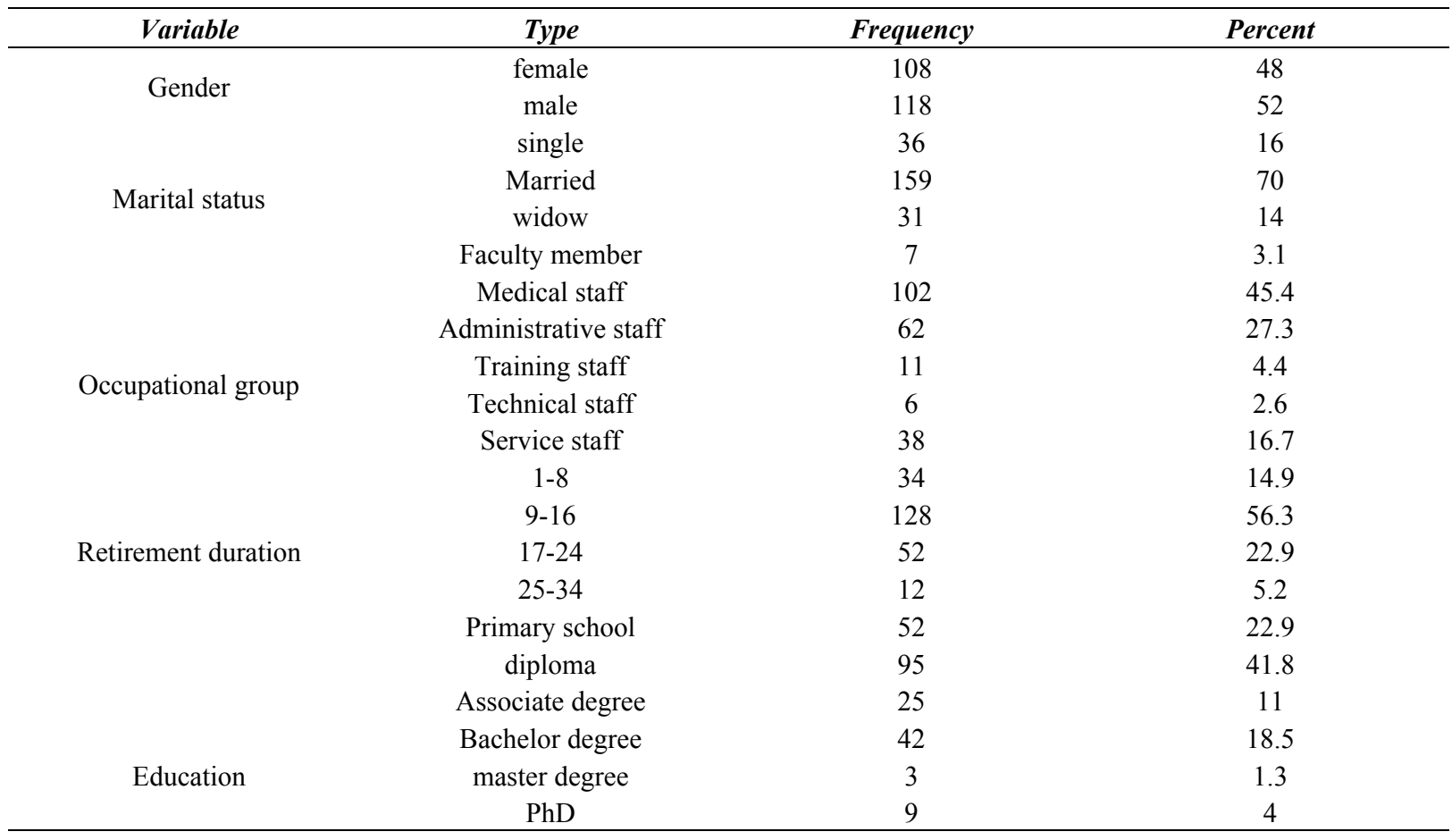

Table 2. Mean and standard deviation of social well-being dimension and life quality

\begin{tabular}{cccc}
\hline Components & Dimensions & Mean & Standard Deviation \\
\hline & Social integration & 2.3 & 0.83 \\
& Social acceptance & 3.5 & 0.94 \\
& Social contribution & 2.4 & 0.96 \\
Social well-being & Social coherence & 2.9 & 0.71 \\
& Social actualization & 2.7 & 0.9 \\
& Physical health & 66.3 & 25.7 \\
& Mental health & 71.3 & 21.6 \\
& Life quality & 68.8 & 21.3 \\
\hline
\end{tabular}

Table 3. Correlation between the social well-being and life quality

\begin{tabular}{ccc}
\hline The dimensions of social well-being & Pearson correlation coefficient & Significance level \\
\hline Social integration & 0.38 & $\mathrm{P}<0.001$ \\
Social acceptance & 0.24 & $\mathrm{P}<0.001$ \\
Social contribution & 0.38 & $\mathrm{P}<0.001$ \\
Social coherence & 0.27 & $\mathrm{P}<0.001$ \\
Social actualization & 0.27 & $\mathrm{P}<0.001$ \\
Social well-being & 0.45 & $\mathrm{P}<0.001$ \\
\hline
\end{tabular}

According to the Pearson correlation coefficient, there is a significant correlation among all the dimensions of social well-being and also between the social well-being and the life quality (Table 3).

Regarding the computed significance level by Pearson correlation coefficient for the variables of age and gender which is respectively $p=0.03$ and $p=0.01$, there is a significant correlation between these two variables and the life quality of the participants $(\mathrm{p}<0.05)$. The computation of significance level for the variables and the life 
quality shows that the marital status $(\mathrm{P}=0.003)$, retirement experience $(\mathrm{P}<0.001)$ are significantly related with the life quality $(\mathrm{P}<0.05)$, but the occupation with the significance level of $\mathrm{P}=0.07$ and education with significance level of $\mathrm{P}=0.1$ are not significantly related with the life quality $(\mathrm{P}>0.05)$.

\section{Discussion}

The results show that the life quality is significantly related with the gender and the men with the life quality mean of 72 benefit from a higher life quality compared with women with the life quality mean of $64\left(\mathrm{R}^{2}: 0.01\right)$; the reason may be the fact that in our society, elderly men participate in the social activities and friends' gathering compared with women and also the social validity and security is higher among the elderly men of the society, so the mean of their life quality is generally higher. The paper titled "the Factors Related with the elderly Life Quality" done by Yazdan pour and Sam Aram in 2010 also confirms the above mentioned relation. The sampling method was systematic random sampling and the data analysis showed that the amount of elderly's dependence on his family and his family's respect to him was related with his life quality. Furthermore, there is a significant correlation between age, gender, marital status, education, his house ownership, his relationship with his family members and the elderly's life quality. In fact, the more supportive is his family, the higher is his life quality (Yzdanpur \& Sam Aram, 2011). The study titles "the Examination of the Relation between Spiritual Health and Life Quality of the Elderly Living in Kahrizak Sanitarium" done by Jadidi et al in 2010 shows the same results. Besides, the findings of the study done by THOMOPOULOU et al in 2010 in order to examine the differences between the life quality and loneliness between the elderly people is matched with the studies of YUASA, while it does not match with Yazdan pour and Sam Aram's study based on the existence of a relationship between the education and life quality.

Regarding the marital status, the study showed that the marital status has been effective on the elderly's life quality. The findings of THOMOPOULO's et al study done in 2010, which examined the relation between life quality and loneliness in different people, also match with this study. In the above mentioned study, the participants were 160 people aged between 60-93 years old living in Greece besides the index of life quality and USLA loneliness index were employed. The findings of the study showed that men's life quality is in a higher position compared with the women's life quality; the elderly, the divorced elderly and the widows had respectively lower life quality and the same result was observed about the loneliness component but the feeling of loneliness was less in divorced elderly compared with the widow people and the final result demonstrated that not having a partner in life will lead to the decrease of personal ability in doing daily affairs and finally life quality.

Regarding the findings of the present study, there is no significant correlation between the occupation and life quality and generally with the social well-being. Occupation is one of the components of people's income. It is evident in the findings of Layte's study that income inequality decreases the validity and also he explain about this fact that in their social interactions, this type of people look at the their partners as a rival and this result in distrust among people; in this study, the social well-being of those people who have ordinary occupation is the highest among others and those people who thought that they are in a better financial status compared with other people, had the lowest social well-being, the reason may be their different beliefs, values and cultural features and also the people who had average or even poor financial status interact more with their friends and other society members. The interesting point in the findings of the study of determination of life quality criteria is that the mean of mental health (71.3) is more than the mean of physical health (66.3). Regarding the relation between the life quality and social well-being, the findings showed that there is a significant correlation between these two. The findings of the study titled "The Cause and Effect Relation between the Related Factors with Physical health, Mental Health and Social Well-being among the Japanese Elderly" done by Yuasa et al in 2011 is completely matched with the findings of the present study. The findings of Yuasa's research demonstrated that the physical health is considerably affected by the social well-being and mental health and it seems that the social well-being in men is more than women. Keeping physical health may be related with supporting the mental health and social well-being (Vahdaninia et al., 2005).

In the present study, social actualization which is a part of social well-being, is significantly related with the life quality, it means that as the life quality improves, the social actualization will be more; if the social actualization is considered as one of the manifestation of spiritual health, then the findings of present study are compatible with Jadidi's et al study which showed that the mean of life quality of the Elderly has been in the average point and the mean of life quality of men is considerably higher than women. Besides, the level of spiritual health of most of the people was high or average and also the mean of their spiritual health was also average and also the findings showed that the spiritual health is significantly correlated with the elderly life quality. 


\section{Conclusion}

Generally speaking, all the five components of social well-being were significantly related with the life quality. The existence of significant correlation between the social well-being and the life quality implies the great importance of social well-being in all the five components among the elderly. The results of the study show that the policy-makers and planners should create a kind of active integration and balance based on the existing facilities and devices and also they should use a suitable advertisement system in order to skip the cultural problems, improve the social relations and correlations and besides in order for the improvement, growth and expansion of the voluntary activities, they can employ the public areas, informal participation like holding religious ceremonies. Furthermore, the support of insurances like health care, pensions for elderly can lead to the financial independence of the elderly.

\section{Limitations of the Study}

1. Since the participants of the study were very old, it was not possible fully concentrate on answering the research questions. Of course the limitation was removed with the cooperation of retirement of centers and creation of facilities for the respondents.

2. The distribution of information and statistics related with the retirees and also lack of a comprehensive information system to solve this problem caused the researcher to use the available sampling.

\section{Acknowledgments}

The Authors would like to thank all participants for their kind cooperation with the researchers in collecting the data.

\section{References}

Ahmadi, F., Salar, A., \& Faghihzadeh, S. (2004). Quality of life in Zahedan elderly population. HAYAT, 10(3), 61-67.

Alipor, F., Sajadi, H., Forozan, A., \& Biglarian, A. Role of Social Ssupport in Quality of Life of Eldely. REFAHE EJTEMAEE, 9(33).

Callaghan, L. (2008). Social Well-Being in Extra Care Housing: An Overview of the Literature. Personal social service research unit,established at the universityof kent an Canterbury.

Darvishpoor Kakhki, A., Abed Saeedi, J., Delavar, A., \& Saeed-O-Zakerin, M. (2010). Tools for measurement of health status and quality of life of elderly people. Pejouhesh, 33(3), 162-173.

Hatami, P. (2010). Studying The Effectual Factors In Social Health of Students Emphasizing of Social Networks (Master of art in Social Work). Allameh Tabataba'i University Faculty of social sciences, Tehran.

Improving the Quality of Life of Elderly and Disabled People in Human Settlements. (1993). (Vol. 1). United Nations Centre for Human Settlements.

Ishaghi, R., \& Zamani, N. (2011). Design and evaluation of health related questionaire in elderly. Journal of Isfahan Medical School, 29(160).

Keyes, C. (1998). Social Well-Being. Social Psychology Quarterly, 61(2), 121-140. http://dx.doi.org/10.2307/ 2787065

Maddah, S. B. (2009). Social activity conditions and leisure-times spending among the Iranian and Swedish elderly. Iranian Elderly Magazine, 3(8).

McGregor, S. L. T., \& Goldsmith, E. B. (1998). Expanding our understanding of quality of life, standard of living, and well-being. Family and Consumer Sciences, 90(2).

Moheghi Kamal, H., Sajadi, H., Zare, H., \& Biglarian, A. (2008). Need assessment among the elders of social security organization \& national retirement fund. Iranian Elderly Magazine, 7(3), 8-15.

Montazeri, A., Goshtasbi, A., \& Vhdany Nia, m. (2005). translation, reliability and validity of standard instrument SF-36 in Persian. Payesh, 5(1).

Nikvarz, T. (2011). The study of Relationship between social capital and the rate social well-being among girl and boy students of Shahid Bahonar University of kerman (Master of Science). Shahid Bahonar kerman.

Oliver, J., Huxley, P., Bridges, K., \& et al. (Eds.). (1997). Quality of life and mental health services. London: Routledge.

Salehi, L., Salaki, S., \& Alizadeh, L. (2012). Health-related Quality of Life among Elderly Member of Elderly 
Centers in Tehran. 8(1), 14-20.

Sharifirad, G., Khalili, F., Sam, S., Hassanzadeh, A., \& Kazemi, M. (2011). The Relationship between Perceived Social Support and Social Health of Elderly. Health System Research, 7(6).

Usefy, A. R., Ghassemi, G. R., Sarrafzadegan, N., Mallik, S., Baghaei, A. M., \& Rabiei, K. (2010). Psychometric Properties of the WHOQOL-BREF in an Iranian Adult Sample. Community Mental Health Journal, 46(2), 139-147. http://dx.doi.org/10.1007/s10597-009-9282-8

Vahdaninia, M., Goshtasbi, A., Montazeri, A., \& Maftoun, F. (2005). Health-related quality of life in an elderly population in Iran: a population-based study. Payesh, 4(4), 113-120.

Yzdanpur, F., \& Sam Aram, E. (2011). Factors associated with quality of life for seniors-seniors khomein County. Social welfare \& development planning, 6, 45-63.

Zilochi, M., MH, PorReza, A., \& Akbari, F. (2011). Inpatient hospital services utilization of elderly people in Kashan University of Medical Sciences. Journal of Hospital, 10(1), 63-70.

\section{Copyrights}

Copyright for this article is retained by the author(s), with first publication rights granted to the journal.

This is an open-access article distributed under the terms and conditions of the Creative Commons Attribution license (http://creativecommons.org/licenses/by/3.0/). 